\title{
Proposta de modernização sustentável do modelo produtivo do farelo do coco babaçu de uma reserva agroextrativista do Maranhão, Brasil
}

Proposal for sustainable modernization of the productive model of babassu coconut bran from an agroextractive reserve in Maranhão, Brazil

Propuesta de modernización sostenible del modelo productivo de salvado de coco babasú de una reserva agroextractiva en Maranhão, Brasil

Carlos Alberto Andrade Serra dos Santos ORCID: https://orcid.org/0000-0003-2436-3677 Universidade Estadual da Região Tocantina do Maranhão, Brasil E-mail: carlos.santos@uemasul.edu.br

Ruan Carlos Gonçalves Saldanha ORCID: https://orcid.org/0000-0002-2362-7995 Universidade Estadual da Região Tocantina do Maranhão, Brasil E-mail: ruansaldanha.2017107300@uemasul.edu.br

Welerson Silva Costa

ORCID: https://orcid.org/0000-0001-6699-3963 Universidade Estadual da Região Tocantina do Maranhão, Brasil E-mail: welersoncosta.2017107310@uemasul.edu.br

Diogenes Fontenele Ferreira Junior ORCID: https://orcid.org/0000-0003-1362-064X Universidade Estadual da Região Tocantina do Maranhão, Brasil E-mail: diogenes.junior@uemasul.edu.br José de Ribamar Macedo Costa ORCID: https://orcid.org/0000-0001-7611-6622 Universidade Federal do Maranhão, Brasil E-mail: macedo.jose@ufma.br

Ivo Almeida Costa

ORCID: https://orcid.org/0000-0002-9227-1240 Universidade Estadual da Região Tocantina do Maranhão, Brasil E-mail: ivo.costa@uemasul.edu.br

Bruno Lucio Meneses Nascimento ORCID: https://orcid.org/0000-0002-7196-6502 Universidade Estadual da Região Tocantina do Maranhão, Brasil

E-mail: bruno.nascimento@uemasul.edu.br

Pedro de Freitas Façanha Filho ORCID: https://orcid.org/0000-0003-4979-7287 Universidade Federal do Maranhão, Brasil E-mail: pedro.facanha@ufma.br

\begin{abstract}
Resumo
Este trabalho tem por objetivo apresentar uma proposta de modernização sustentável do modelo produtivo do farelo do coco babaçu, como fonte de ampliação de renda para comunidade extrativista do Ciriaco - MA. Foram utilizadas observações da rotina de trabalho da comunidade extrativista do Ciriaco e entrevista com o coordenador da ATARECO para conhecer o processo de fabricação dos produtos derivados do babaçu. Os resultados demostraram que os trabalhadores extrativistas têm desperdiçado o potencial econômico do endocarpo por descartar no processo de extração da amêndoa babaçu. A cadeia atual de produção do local de estudo não possui estrutura para grandes demandas produtivas devido a maior parte desse processo ser realizado de forma manual. A produção de processamento diária na RESEX através do tradicional é em média $300 \mathrm{~kg} / \mathrm{dia}$ do coco babaçu, já com a incorporação do maquinário a capacidade de processamento passa a ser $20.000 \mathrm{~kg}$ de coco in natura por dia. Desta forma, existe a necessidade de incorporar tecnologias nas atividades extrativistas com o intuito de impulsionar a fabricação e consequentemente a renda das famílias extrativistas. Sendo assim, esse trabalho possui relevância por levantar indicadores sobre a contribuição da fabricação mecanizada de farelo derivado do epicarpo, mesocarpo, e endocarpo do coco babaçu, para ampliação sustentável da renda das comunidades que tem o extrativismo do babaçu como meio de subsistência.
\end{abstract}

Palavras-chave: Babaçu; Pericarpo; Ciriaco; Sustentabilidade. 


\begin{abstract}
This paper aims to present a proposal for sustainable modernization of the productive model of babassu coconut bran, as a source of income expansion for the extractivist community of Ciriaco - MA. Observations of the work routine of the extractivist community of Ciriaco were used and an interview with the ATARECO coordinator to learn about the manufacturing process of products derived from babassu. The results showed that extractive workers have wasted the economic potential of the endocarp by discarding the process of extracting babassu almonds. The current production chain at the study site has no structure for large production demands because most of this process is carried out manually. The daily processing production at RESEX through the traditional is an average of $300 \mathrm{~kg} / \mathrm{day}$ of babassu coconut, with the incorporation of machinery, the processing capacity becomes $20,000 \mathrm{~kg}$ of fresh coconut per day. Thus, there is a need to incorporate technologies in extractive activities in order to boost manufacturing and, consequently, the income of extractive families. Therefore, this work has relevance for raising indicators on the contribution of mechanized bran production derived from epicarp, mesocarp, and endocarp of babassu coconut, for the sustainable expansion of the income of communities that have babassu extractivism as a means of subsistence.
\end{abstract}

Keywords: Babaçu; Pericarp; Ciriaco; Sustainability.

\title{
Resumen
}

Este trabajo tiene como objetivo presentar una propuesta de modernización sostenible del modelo productivo del salvado de coco babasú, como fuente de expansión de ingresos para la comunidad extractivista de Ciriaco - MA. Se utilizaron observaciones de la rutina de trabajo de la comunidad extractivista de Ciriaco y una entrevista con el coordinador de ATARECO para conocer el proceso de fabricación de productos derivados del babasú. Los resultados mostraron que los trabajadores extractivos han desperdiciado el potencial económico del endocarpio al descartar el proceso de extracción de almendras babasú. La cadena de producción actual en el sitio de estudio no tiene estructura para grandes demandas de producción porque la mayor parte de este proceso se lleva a cabo manualmente. La producción de procesamiento diario en RESEX a través del tradicional es un promedio de $300 \mathrm{~kg} /$ día de coco babasú, con la incorporación de maquinaria, la capacidad de procesamiento pasa a ser de $20.000 \mathrm{~kg}$ de coco fresco por día. Por lo tanto, existe la necesidad de incorporar tecnologías en las actividades extractivas para impulsar la manufactura y, en consecuencia, los ingresos de las familias extractivas. Por lo tanto, este trabajo es relevante para levantar indicadores sobre la contribución de la producción mecanizada de salvado derivado del epicarpio, mesocarpio y endocarpio del coco babasú, para la expansión sostenible de los ingresos de las comunidades que tienen el extractivismo del babasú como medio de subsistencia.

Palabras clave: Babaçu; Pericarpio; Ciriaco; Sustentabilidad.

\section{Introdução}

O processo de expansão das civilizações teve como aporte de desenvolvimento o uso dos recursos naturais para construção de espaços urbanos (Monteiro, 2020). Com isso, os ecossistemas tiveram modificações definitivas na paisagem por conta da supressão das áreas de florestas, desvio dos percursos hídricos, extração de recursos minerais, e emissão de poluentes atmosféricos (Hao et al., 2017; Zhang et al., 2020).

A relação entre habitat e moradia nortearam uma divisória na perspectiva da ocupação dos espaços, assim, o ser humano por possuir maior capacidade organizacional idealizou seu status de convivência acima dos demais seres vivos (Meek \& Simonian, 2017; de Sousa Sousa, 2020). Com o crescimento populacional e o fenômeno da globalização o ritmo de consumo dos recursos acelerou e com isso as fontes naturais começaram a mostrar os primeiros sinais de escassez (Brown et al., 2002; May \&Vinha, 2010; Solón, 2019).

Uma Unidade de Conservação (UC) possui como finalidade a proteção de partes consideráveis do meio ambiente que possuem significância para a dinâmica do habitat, ecossistema, comunidade, e biosfera, a fim de conservar o patrimônio biológico que é fundamental para manter um ambiente saudável e ecologicamente equilibrado (Costa et al., 2018; Wintle et al., 2019). As primeiras atividades de conservação e preservação do meio ambiente no Brasil aconteceram no século XVII, com intuito de proteger as floretas da região nordestina, destacando a importância de impedir o desmatamento florestal no Nordeste (Borba \& Lüchmann, 2017). Todos os elementos que constituem um ecossistema atuam para o meio em que está inserido, nenhum indivíduo é um componente separado da biosfera, então, o que se pretende alcançar é o equilíbrio entre as atividades executadas nos diferentes ambientes (Teixeira et al., 2020).

O extrativismo é uma atividade constituída de três fases distintas, onde a primeira fase é caracterizada pelo aumento 
da extração, transformando os recursos naturais em recursos econômicos de acordo com demanda aumenta. Na segunda fase, atinge-se o limite da capacidade de abastecimento, devido à redução da disponibilidade de estoques e ao aumento do custo de extração, devido à escassez das melhores áreas. Na terceira fase e última fase é inicia-se o declínio da extração, com o esgotamento das reservas e o aumento da demanda levando ao início do plantio, desde que haja a tecnologia de domesticação disponível e seja viável economicamente. Diversas plantações foram iniciadas por populações tradicionais e povos indígenas, que identificaram de acordo com características de interesse as melhores plantas, e posteriormente realizadas por instituições de pesquisa (Homma, 2012). O aumento da densidade populacional, a expansão das fronteiras agrícolas, a criação de alternativas economicamente viáveis, o processo de degradação e o surgimento de produtos substitutos também são fatores indutores desse declínio (Homma, 2012, Mora-Motta \& Stellmacher, 2020).

O babaçu é uma palmeira muito conhecida entre populações brasileiras tradicionais e gera um fruto chamado de coco babaçu, onde este, varia de nomenclatura de região para região do país, podendo ser chamado também de guaguaçu, uauaçu, gebara-uçu, coco-de-macaco, coco-de-palmeira, coco-naiá, dentre vários outros nomes (Carneiro et al., 2014; Araujo et al., 2020).

As variedades de babaçu possuem grande importância por seus aspectos, ambientais, sociais, ecológicos e econômicos (Araujo et.al., 2020). O coco babaçu (Orbignya speciosa) é constituído pelo pericarpo que possui três camadas distintas: epicarpo (mais externa), mesocarpo (intermediária) e endocarpo (mais interna) (Chitarra \& Chitarra, 2006) e amêndoas (Santos et al., 2020). Em geral o mesocarpo é a parte do fruto que mais se desenvolve, sintetizando e acumulando substâncias nutritivas, principalmente açucares (Tsuji et al., 2019). Atualmente o coco babaçu é coletado e descascado manualmente por mulheres e crianças, sendo um dos problemas sociais da região Nordeste/Norte do Brasil (de Oliveira Melo et al., 2020).

A exploração do babaçu é uma atividade de extrativismo vegetal que possui importância social, política, cultural e econômica no Brasil onde os babaçuais ocupam uma área de conservação que abrange 18 milhões de hectares do território brasileiro. (Porro, 2019: Teixeira et al., 2019). O Maranhão é o Estado que mais produz babaçu, dentre os municípios maranhenses líderes em produção destaca-se: Vargem grande, Pedreiras, Porção de Pedra, Bacabal, Paulo Ramos, Lago dos Rodrigues e Joselândia (da Silva Saraiva et al., 2019; IBGE, 2019).

A prática de extração e comercialização do babaçu tradicionalmente é ligado as quebradeiras de coco, considerado como atividade exercida por mulheres para contribuir com a produção doméstica (Soares \& Arruda, 2018). Os primeiros grupos de exploração do babaçu eram exclusivamente de mulheres, pois os membros masculinos das comunidades rurais trabalhavam diretamente com agricultura (Ribeiro \& Mittmann, 2020). Como figuras representantes dessa atividade econômica a comunidade tradicional local é organizada pela Associação dos trabalhadores Agroextrativistas da Reserva Extrativista do Ciriaco (ATARECO) (dos Santos, 2019). As Reservas Extrativistas (RESEX) são territórios protegidos pelo poder público que permite uma determinada comunidade utilizar os recursos naturais desses espaços de maneira sustentável como meio de subsistência (de Almeida et al., 2018).

A Reserva Extrativista do Ciriaco ou também conhecida como RESEX do Ciriaco é de âmbito federal classificado como uma Unidade de Conservação pelo decreto presidencial de $\mathrm{n}^{\circ} 4.340 / 02$, tendo em vista o disposto na Lei $\mathrm{n}^{\circ} 9.985$ de julho de 2000 que determina o ato de criação da Unidade de Conservação (UC). Inicialmente a criação da RESEX do Ciriaco foi instituída através do decreto ${ }^{\circ} 534 / 92$, essa conquista se deu como resultado das articulações feitas pelos movimentos sociais da região, nos dias de hoje é uma área que corresponde a 8.106,75 hectares (ICMBIO, 2010). As mudanças no uso e cobertura da terra na região vem acontecendo com o acréscimo da instalação de novas propriedades e progresso da urbanização. Fenômeno impulsionado em 2010 pelo início das atividades da empresa Suzano na região que provocou ampliação dos fluxos originários da sua instalação, expansão imobiliária, ocupações desordenadas, exploração mineral e 
vegetal, possibilitando significativa modificações na dinâmica local (Masulo, 2019).

Apesar da prática extrativista do babaçu ser considerada símbolo da comunidade o número de famílias extrativistas vem diminuindo a cada ano, de acordo com dados do ICMBIO das 160 famílias cadastradas apenas 60 continuam com a quebra de coco babaçu, por conta do baixo retorno financeiro. Por ser uma atividade que possui vários processos manuais que demandam uma ampla carga horária de trabalho a quebra do coco babaçu tem sido desvalorizada na RESEX, dando espaço as atividades agropecuárias (Florentino et al., 2016). A falta de estruturas que possibilitam o desenvolvimento pessoal e social tem contribuído para os membros da comunidade se mudarem para outras localidades em busca de melhor qualidade de vida. Assim, o presente estudo traz uma proposta de modernização sustentável do modelo produtivo do farelo do coco babaçu para ampliação de renda econômica, que podendo contribuir para o desenvolvimento pessoal e social dos trabalhadores da RESEX do Ciriaco devido sua importância na preservação ambiental e cultural.

\section{Materiais e Métodos}

\subsection{Tipo do estudo}

Este trabalho é de natureza exploratória e descritiva, pois de acordo com Pereira, Shitsuka, Parreira \& Shitsuka (2018) as pesquisas descritivas vão além da simples identificação da existência de relações entre variáveis, pretendendo determinar a natureza dessa relação, e as exploratórias tem por finalidade identificar a relação do problema com os dados da fonte obtida aproximando a pesquisa da complexidade do problema. A pesquisa foi realizada na reserva extrativista do Ciriaco, que pertence ao município de Cidelândia no estado do Maranhão.

\subsection{Caracterização da área do estudo}

Reserva Extrativista do Ciriaco está situada no sudoeste do estado do Maranhão com um território que abrange os municípios de Imperatriz e Cidelândia, com Latitude $05^{\circ} 18^{\prime} 53^{\prime \prime}$ S e Longitude: $47^{\circ} 48^{\prime}$ 35" W (IBGE, 2019). Cidelândia foi elevada à condição de município na data de 10 de novembro de 1994, através da Lei №. 6.142. O município limita-se a Leste, com os municípios de Açailândia e São Francisco de Brejão; a Oeste, com o Estado do Tocantins e com o município de Vila Nova Dos Martírios, ao Sul, com o município de Imperatriz e ao Norte com o Estado do Pará (IBGE, 2020). Sua população estimada no ano de 2020 foi de 14.777 pessoas, possuindo população e densidade demográfica no último censo de 2010 no total de 13.681 pessoas e 9,34 hab/km² respectivamente (IBGE, 2020). Segundo a classificação internacional de Koppen e Geiger o clima regional é classificado como Clima tropical com estação seca - Aw (Alvares et al., 2013). Na Figura 1 observamos (a)Imagem de satélite da Reserva Extrativista do Ciriaco e (b) Localização geográfica da reserva no Estado do Maranhão. 
Figura 1 - (a)Imagem de satélite da Reserva Extrativista do Ciriaco (b) Localização geográfica da reserva no Estado do Maranhão.

(a)

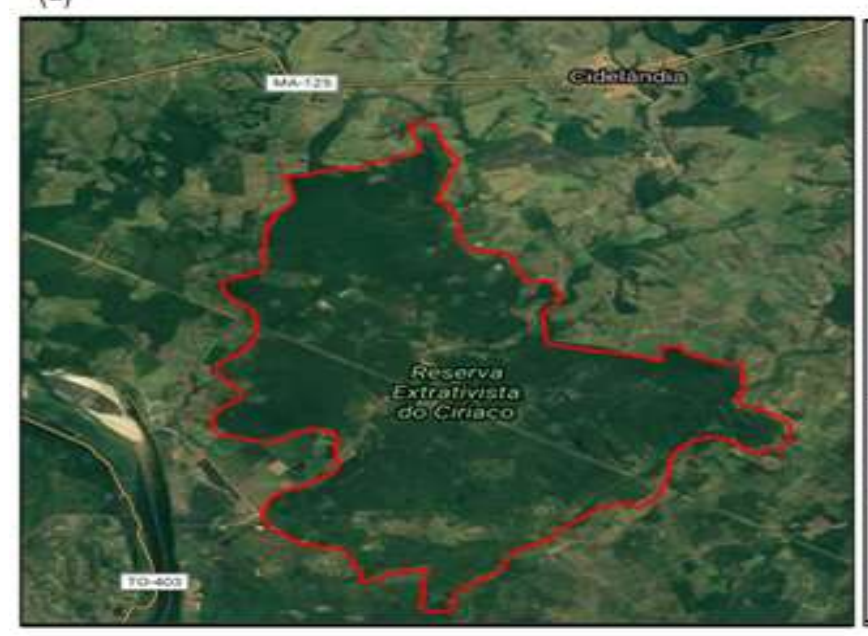

(b)

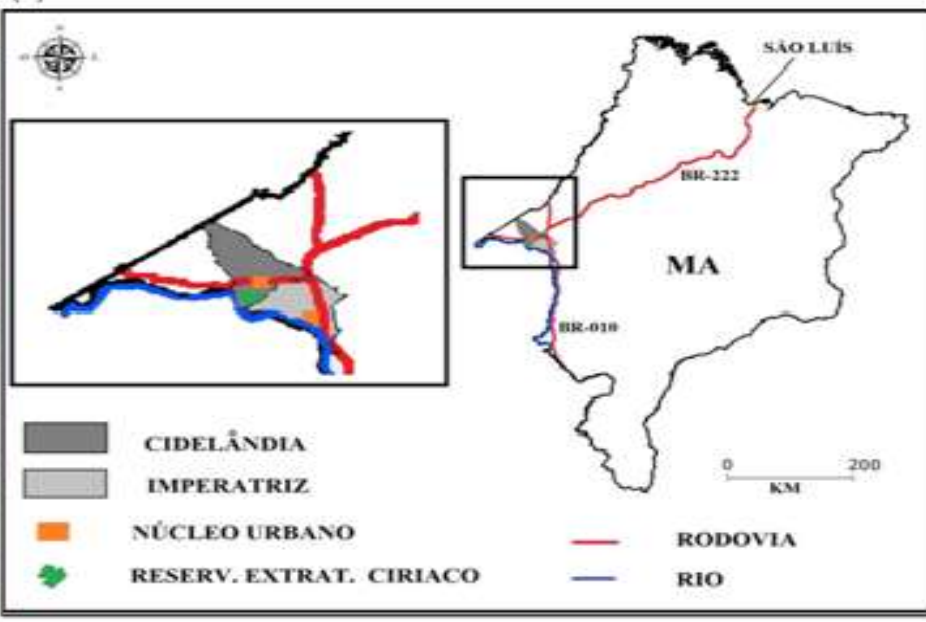

Fonte: Google Earth (2020); Oliveira (2018), adaptado pelos autores.

Na Figura 2 abaixo observa-se a Sede da Associação dos trabalhadores Agroextrativistas da Reserva Extrativista do Ciriaco (ATARECO) que se encontra em fase de reforma estrutural. A reserva é uma das nove primeiras Unidade de Conservação criadas do Maranhão, sua constituição se deu pela articulação popular aliada com organizações não governamentais, com intuito de proteger o meio de vida da população extrativista local. Sua área de abrangência se encontra nos municípios de Cidelândia e Imperatriz, as atividades econômicas desenvolvidas nessa região, além da extração de coco babaçu, é a agricultura e criação de gado (dos Santos, 2019).

No entorno da Resex do Ciriaco, as comunidades e propriedades particulares (fazendas) possivelmente são prejudiciais para a sustentabilidade da UC, devido aos impactos produzidos pelas práticas de silvicultura e pecuária, pelo aumento de atividades econômicas na região e pelo tráfego de veículos e de pessoas. Estes efeitos, tais como o aumento da caça ilegal, do desgaste do solo, da quantidade de lixo produzido e do uso inadequado das águas, têm se acentuado nos últimos anos prejudicando assim que região tenha um desenvolvimento sustentável (Santos et al., 2021).

Figura 2 - Sede da Associação dos trabalhadores Agroextrativistas da Reserva Extrativista do Ciriaco (ATARECO).

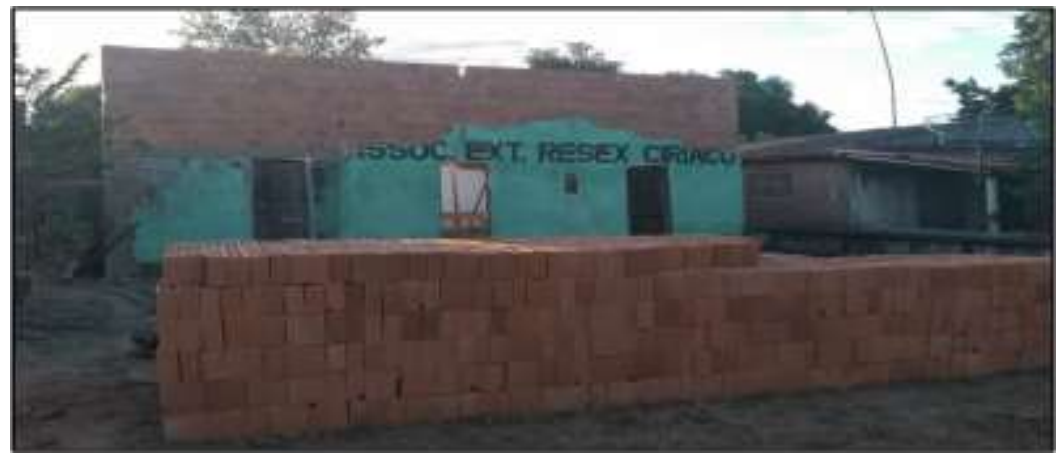

Fonte: Autores (2020). 


\subsection{Critérios para inclusão e exclusão da amostra}

Os critérios de exclusão e inclusão e estão interligados, assim, é possível afirmar que "critérios de inclusão" são os requisitos utilizados numa pesquisa como forma de selecionar os sujeitos que serão convidados a participar, justamente por suas características peculiares e subjetivas. Já os "critérios de exclusão" serão as características observadas nos sujeitos selecionados como impedimento de participação na pesquisa, assim, não atendendo aos propósitos da pesquisa, por possuírem um estado que os excluem daquele grupo que está apto a participar (Patino. \& Ferreira, 2018).

A Reserva Extrativista do Ciriaco foi escolhida como local de estudo por ser a região extrativista que tem da produção anual de 400 toneladas menos de 10\% ao ano, de acordo com os dados divulgados no último censo do IBGE (2018). Com isso, surge a necessidade de elaborar novas alternativas para implementar a fonte de renda dessa comunidade extrativista, devido sua importância na preservação ambiental e cultural. Os critérios para inclusão na amostra foram: ser cadastrado na Associação dos Trabalhadores Agroextrativistas da Reserva Extrativista do Ciriaco (ATARECO), aceitar participar da pesquisa de forma voluntária, ser maior de 18 anos. Os critérios que não atenderam aos critérios de inclusão da amostra foram considerados de exclusão e consequentemente não participaram da pesquisa.

\subsection{Estratégia de coleta de dados}

Após a escolha do local de estudo realizou-se a pesquisa de campo, nos meses de fevereiro a março de 2020, que consistiu em coletar dados diretamente na localidade do objeto de pesquisa, fazendo uso de observações, entrevista verbal na modalidade de questionário e registros fotográficos. Sobre a entrevista, utilizou-se um questionário estruturado com dez perguntas dissertativas, aplicadas ao coordenador geral da Associação dos trabalhadores Agroextrativistas da Reserva Extrativista do Ciriaco. O questionário possuía as seguintes perguntas listadas abaixo:

1. Qual é a produção anual de babaçu?

2. Quantas famílias são associadas?

3. A associação trabalha com produção de óleo de babaçu? Se sim, qual é o processo?

4. Tem produção de farinha derivada do babaçu? Se sim, como é feito a fabricação?

5. Qual o tempo estimado usado no processo de secagem exposto ao sol?

6. O epicarpo é utilizado? Se sim, em que?

7. O endocarpo é utilizado? Se sim, em que?

8. Sabendo do uso do endocarpo, por que então ele é descartado?

9. Na sua perspectiva qual a importância da extração do coco babaçu?

10. Na sua opinião o que é necessário para impulsionar a comercialização dos produtos fabricado pela comunidade extrativista do Ciriaco?

A finalidade da entrevista foi coletar informações sobre atual modelo de produção desenvolvido na RESEX do Ciriaco, conhecer as estratégias e processos logísticos, além dos produtos comercializados pelos associados, para que dessa forma pudéssemos apresentar uma proposta de melhoria tecnológica desse modelo produtivo através da utilização de todo o pericarpo (epicarpo, endocarpo e mesocarpo) da matéria prima abundante na reserva (coco babaçu) mediante a utilização de um conjunto de máquinas como alternativa sustentável de ampliação da renda econômica. As respostas encontram-se na seção resultados e discussão.

\section{Resultados e Discussão}

Nesta seção apresentamos uma proposta melhoria do modelo produtivo utilizado na ATARECO através do uso de todo o pericarpo (epicarpo, endocarpo e mesocarpo) do coco babaçu para a produção do farelo mediante o uso de maquinário 
específico sem alto custo financeiro e de fácil operação que modernize e aumente a produção como alternativa sustentável de ampliação da renda econômica.

\subsection{Produção manual e produtos comercializados pela ATARECO}

Por ser uma atividade que utiliza vários processos manuais. que demandam uma ampla carga horária de trabalho, a quebra do coco babaçu tem sido desvalorizada na RESEX, dando espaço as atividades agropecuárias. O modo tradicional feito pelas quebradeiras de coco começa com a separação da amêndoa, após isso é colocado no forno de lenha por alguns minutos, em seguida é batido no pilão até apresentar uma consistência pastosa. Após adquirir essa consistência, é inserido em tecido suspenso com um vasilhame em baixo para armazenar o óleo que cai do tecido com material pastoso. A separação manual da amêndoa pode ser observada na Figura 3 abaixo.

Figura 3 - Quebradeiras de coco da Reserva Extrativista do Ciriaco.

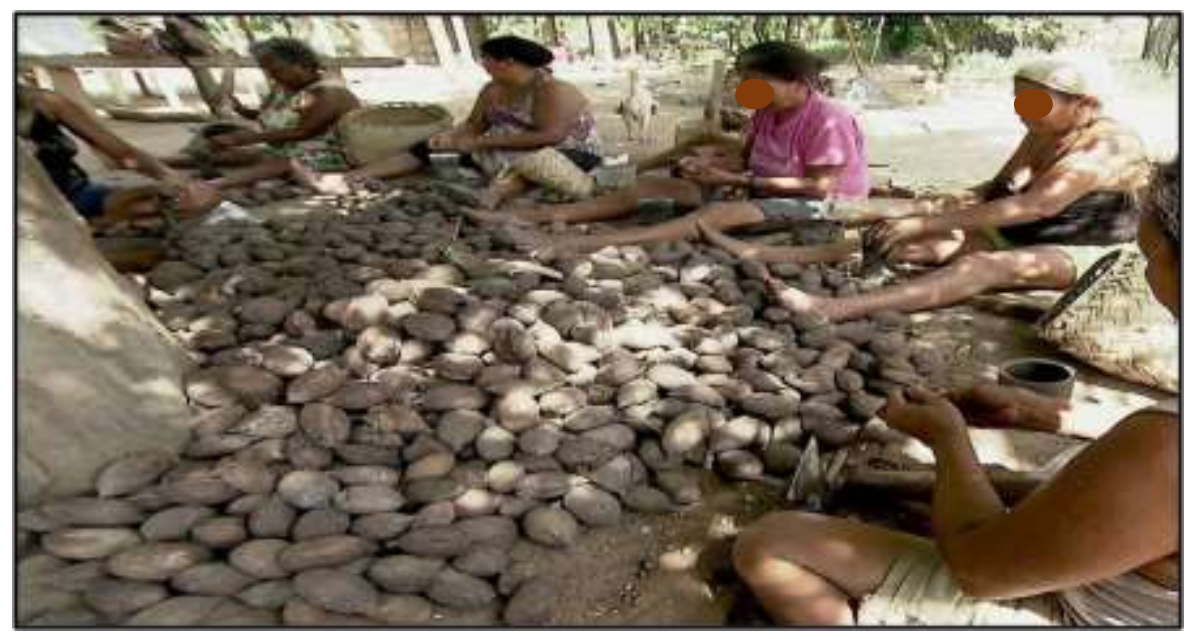

Fonte: Autores (2020).

Dos produtos derivados do babaçu obtém-se o azeite consumido pela própria população da reserva e os que são comercializados no Ciriaco: carvão derivado da casca, amêndoa, farinha do mesocarpo, óleo e peças artesanais feitas de palha ou do endocarpo. A fabricação da farinha (farelo) do mesocarpo é feita de maneira manual, primeiro o mesocarpo é extraído do babaçu, depois é colocado para secar exposto ao sol por três a quatro horas, após esse processo é triturado na forrageira e peneirado. No Quadro 1 abaixo mostramos o preço dos produtos comercializados pela ATARECO segundo a associação de trabalhadores.

Quadro 2 - Valor dos produtos comercializados pela ATARECO.

\begin{tabular}{|l|l|l|}
\hline \multicolumn{1}{|c|}{ Produto } & Unidade & Valor (R\$) \\
\hline Óleo & por litro & 15,00 \\
\hline Carvão & por quilograma & 8,00 \\
\hline Chapéu de palha & por peça & 30,00 \\
\hline Chaveiro & por peça & 7,00 \\
\hline Farinha do mesocarpo & por quilograma & 3,00 \\
\hline
\end{tabular}

Fonte: Autores (2020). 
Uma parte desse processo observado na Figura 3 demanda muito tempo e um grande esforço físico por parte das quebradeiras de coco, assim, a melhoria desse processo produtivo com a introdução da mecanização, resultaria em uma melhor qualidade de vida para esta comunidade além de maior retorno financeiro devido ao aumento da produção, justificado assim a proposta desse estudo.

\subsection{Respostas do questionário}

Q. 1 - Qual é a produção anual de babaçu?

"R. Não temos um valor exato, mas o valor em média é de 32 toneladas."

Q. 2 - Quantas famílias são associadas?

"R. São 160 famílias cadastradas, mas em atividade temos apenas 60 famílias."

Q. 3 - A associação trabalha com produção de óleo de babaçu? Se sim, qual é o processo?

"R. Sim, são produzidos azeite e óleo, porém o azeite é feito apenas para consumo próprio. O início do processo de produção do óleo é igual a produção do azeite, primeiro o coco é quebrado para tirar a amêndoa, daí por diante só aqueci a amêndoa um pouco que depois é colocado na prensa, daí pega o óleo e deixa decantar por 5 ou mais dias para ter óleo mais purificado."

Q. 4 - Tem produção de farinha derivada do babaçu? Se sim, como é feito a fabricação?

"R. Sim, é tirado o mesocarpo, que é uma massa, e colocado para secar no sol, nesse tempo é observado a massa para não deixar secar muito, e depois passa na forrageira e na peneira bem peneiradinha para ter a farinha."

Q. 5 - Qual o tempo estimado usado no processo de secagem exposto ao sol?

"R. O tempo que ele fica secando não tem um tempo estimado, mas fica observando para não deixar secar muito. Ele pode ser secado ao sol ou em uma estufa, mas como aqui ninguém tem estufa então é feito do modo tradicional."

Q. 6-O epicarpo é utilizado? Se sim, em que?

"R. Não, ele é descartado, mas ele pode ser utilizado como adubo ou adicionado na ração para gado e frango."

Q. 7 - O endocarpo é utilizado? Se sim, em que?

"R. Sim, do endocarpo é feito carvão."

Q. 8 - Sabendo do uso do endocarpo, por que então ele é descartado?

"R. Porque não temos treinamento e equipamento adequado para fazer esses produtos. Se um dia despertar o interesse precisaremos de um planejamento e financiamento adequado."

Q. 9 - Na sua opinião o que é necessário para impulsionar a comercialização dos produtos fabricado pela comunidade extrativista do Ciriaco?

"R. Eu acho que deveria ter mais apoio e incentivo fiscal do poder público. Também deve ser melhorado as condições das estradas, pois o acesso é dificultado quando é tempo de chuva, e também traz muito problema para os veículos de transporte, então a gente não consegue expandir a distribuição dos nossos produtos."

Q. 10 - Na sua perspectiva qual a importância da extração do coco babaçu?

"R. A atividade extrativista das quebradeiras de coco tem uma importancia cultural, pois transmite um conhecimento tradicional que tem representação histórica, essa carga histórica representa a luta de várias comunidades. As práticas extrativistas têm se mostrado um importante instrumento para preservar os babaçuais que estão sendo derrubados para criação de pastos."

A respostas indicam que existe a necessidade da melhoria e modernização do processo produtivo na comunidade extrativista do Ciriaco. 


\subsection{Proposta de melhoria na produção do farelo de coco babaçu}

O coco babaçu é composto pelo epicarpo (camada rígida externa), mesocarpo (grande quantidade de amido), endocarpo (envolve as amêndoas) e amêndoas (de onde o óleo é retirado) este pode ser totalmente utilizado. $\mathrm{O}$ farelo de coco babaçu é resultado do processo de industrialização da quebra e trituração, deixando no aspecto físico em pó como mostrado na Figura 4 abaixo, já pronto para ser utilizado na fertilização do solo, ou incorporado na ração para alimentação de aves e vários tipos de animais ruminantes e não ruminantes, assim aumentar essa produção de farelo com um processo mecanizado otimizará esse processo.

Figura 4 - Farelo de coco babaçu.

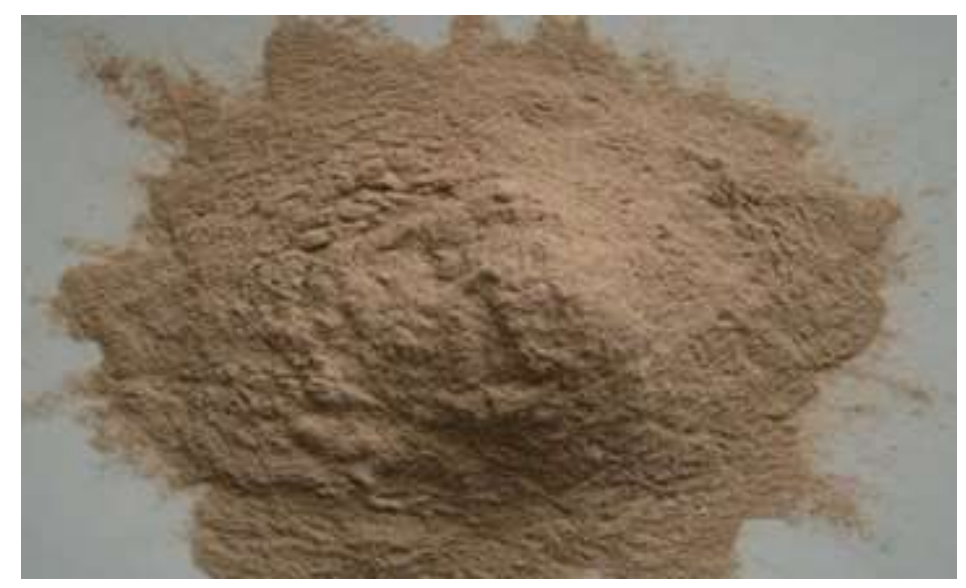

Fonte: Autores (2020).

Desta forma propõem-se para obtenção da farinha a implementação de processos mecanizados onde primeiramente o coco babaçu deve ser coletado na mata pelos associados do ATARECO no período em que está recém caído ou maduro nas palmeiras. Posteriormente, deverá ser transportado para um local onde as partes do coco babaçu serão separadas por um conjunto de máquinas para quebrar coco Babaçu. Esse conjunto de máquinas que pode ser utilizado para dinamizar esse processo é mostrado na Figura 5 abaixo. 
Figura 5 - Conjunto de máquinas utilizado para quebra do coco Babaçu.

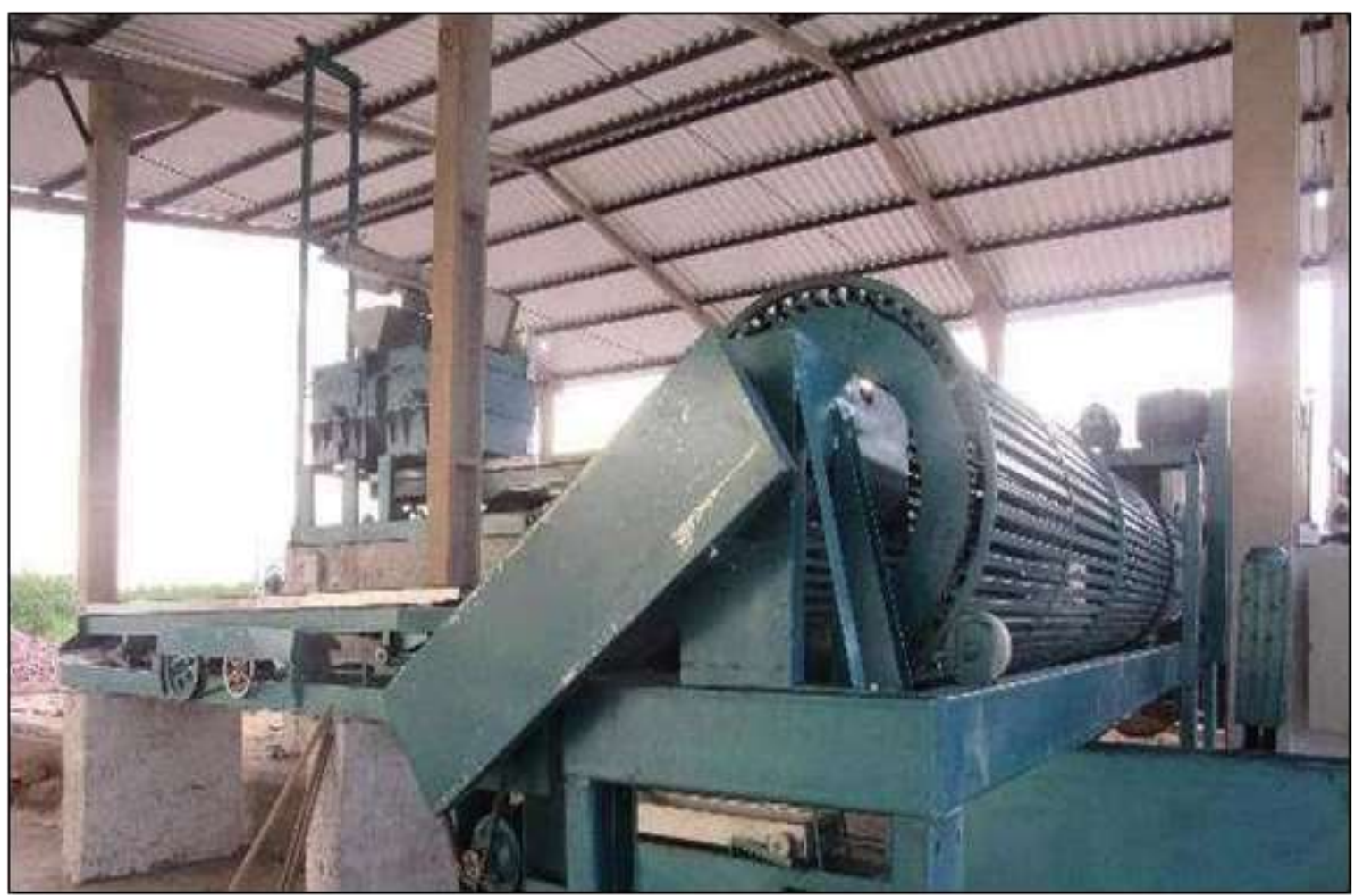

Fonte: MF RURAL (2020).

Esse maquinário é constituído por um elevador, que faz a elevação do coco a partir do silo até a tremonha do descascador. Dois descascadores, utilizados para desagregar fibras e mesocarpo do coco in natura. Uma peneira é utilizada para separar a fibra o amido do endocarpo e as amêndoas. Um quebrador que desagrega o endocarpo das amêndoas. Após isso, outra peneira separa as amêndoas e o endocarpo já desagregados. Um transportador helicoidal é responsável de retornar as amêndoas e o endocarpo não desbragados para o quebrador. Um separador que através de flotação separa o endocarpo das amêndoas. Finalmente uma peneira que separa as amêndoas da água utilizado no processo de flotação (MF RURAL, 2020). Esses equipamentos (nesta configuração) são capazes de processar $20.000 \mathrm{~kg}$ de coco in natura por dia, assim, resultando em uma produção de: 1500 kg de Fibra (epicarpo), 3300 kg Amido, 8800 kg Fração lenhosa (endocarpo), 700 kg Amêndoas (sementes) (MF RURAL, 2020) e podem ser adquiridos através site de vendas da empresa na internet.

Após a segregação do material leva-se para um Triturador Forrageiro TRF 400 2CV 110220V TRAPP mostrado na Figura 6 abaixo. O farelo fabricado dos componentes do coco babaçu deverá ser separado, uma vez que somente a farinha do mesocarpo pode ser destinada para consumo humano. $\mathrm{O}$ farelo obtido a partir da moagem dos demais componentes do coco babaçu serão comercializados como adubo orgânico para fertilização do solo e/ou para incorporação na ração de aves e outros animais. Este equipamento mostrado na Figura 6 é comercializado no site de vendas da empresa na internet. 
Figura 6 - Triturador Forrageiro TRF 400 2CV 110220V TRAPP.

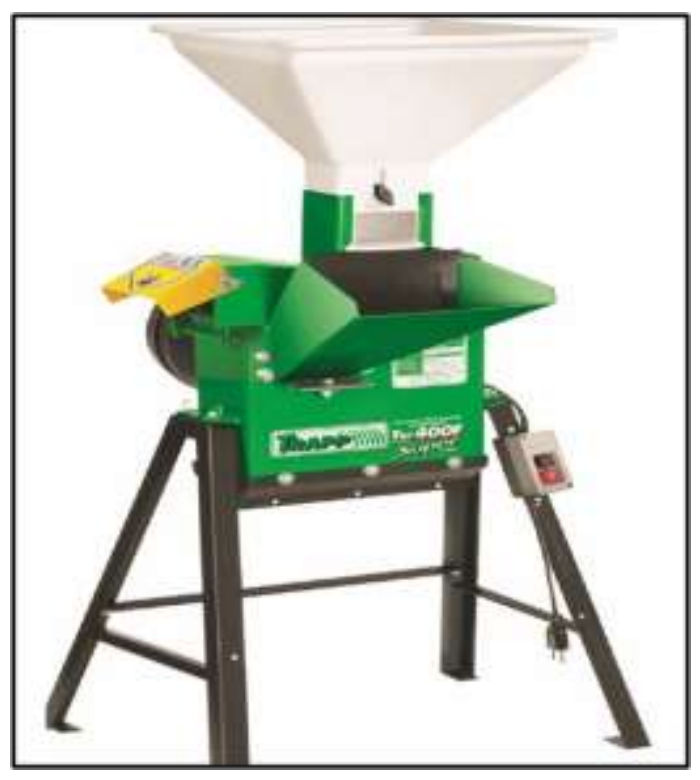

Fonte: Refer Comércio (2020).

A quantidade de farelo (farinha) que pode ser extraída é superior a $5 \mathrm{~kg}$, esta quantidade proveniente de um cacho de babaçu fazendo uso do epicarpo, mesocarpo e endocarpo. Faz-se necessário o empacotamento do farelo, assim, propõe-se utilização de sacos plásticos de polipropileno transparente 10x20 0,06 - 1kg que possuem baixo custo e podem ser facilmente comprados no mercado convencional ou através se sites eletrônicos de vendas. Essas embalagens plásticas podem ser observadas na Figura 7(a).

Figura 7 - (a) Sacos Plásticos de Polipropileno Transparente 10x20 0,06 - 1kg. (b) Seladora Manual de Plástico 40cm PFS 400 .
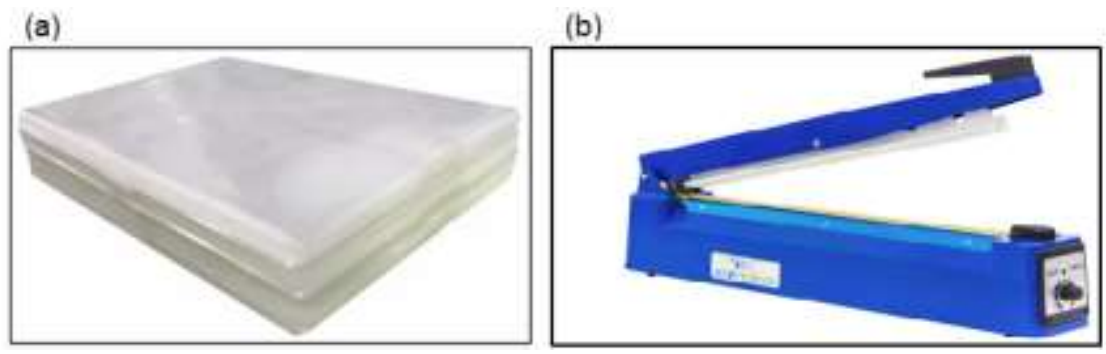

Fonte: Mercado Livre Brasil (2020).

A Figura 7(b) mostra uma seladora manual de plástico 40cm PFS 400 - 12210V da marca Cetro como proposta para vedar a embalagem plástica na qual a farinha foi empacotada, podendo ser vendida a $\mathrm{R} \$ 4,00$ por quilograma (baixo preço) devido a existência de demanda no mercado local. Esta seladora pode ser adquirida através de compra no site Mercado Livre.

O Quadro 2 abaixo mostra o custo total dos equipamentos propostos para a melhoria do modelo produtivo utilizado na ATARECO que atualmente é manual e com capacidade de processamento diário de cerca de $300 \mathrm{~kg} / \mathrm{dia}$. O conjunto de máquinas para separar os componentes do coco babaçu tem preço médio de mercado 149.500,00 reais, um triturador forrageiro TRF 400 2CV 110220V TRAPP custa aproximadamente 1.549,00 reais, cem sacos plásticos de polipropileno transparente 10x20 0,06 - 1Kg custam em média 23,00 reais e uma seladora manual de plástico 40cm PFS 400 possui preço em torno de 183,00 reais. Assim, modernizando o modelo produtivo como proposto neste trabalho pode-se ampliar a capacidade de 
processamento diário para cerca de $20.000 \mathrm{~kg} /$ dia. Essa modernização não possui alto custo financeiro como mostrado no Quadro 2 abaixo. Este investimento médio que totaliza 151.255,00 reais possivelmente pode ter seu custo de implementação pago através do lucro proveniente do aumento da produção que será comercializada.

Quadro 2 - Valor dos equipamentos necessários para produção do farelo do babaçu.

\begin{tabular}{|l|c|c|}
\hline \multicolumn{1}{|c|}{ Equipamento } & Quantidade & Valor (R\$) \\
\hline Conjunto de máquinas para separar os componentes do coco babaçu & 1 & $149.500,00$ \\
\hline Triturador Forrageiro TRF 400 2CV 110220V TRAPP. & 1 & $1.549,00$ \\
\hline Sacos Plásticos de Polipropileno Transparente 10x20 0,06-1Kg. & 100 & 23,00 \\
\hline Seladora Manual de Plástico 40cm PFS 400. & 1 & 183,00 \\
\hline
\end{tabular}

Fonte: Autores (2020).

De acordo com os dados do relatório sobre a quantidade de produtos da extração vegetal e da silvicultura do sistema IBGE de recuperação automática (SIDRA), Cidelândia produziu, nos anos de 2017 e 2018, 34 toneladas de babaçu (IBGE/SIDRA, 2019). Com a implantação de máquinas na cadeia de produção o volume de produto terá um acréscimo podendo fornecer para o mercado regional, e ainda a possiblidade de firmar contrato com empresas multinacionais do ramo.

A região Tocantina do Maranhão tem um fluxo ativo do comercio da agropecuária, com diversas possibilidades de aplicação do farelo derivado do babaçu, como na criação de animais para o abate ou extração de leite, além da fertilização do solo com finalidade para plantio ou reparação, assim tendo diferentes segmentos no mercado. O aproveitamento dos componentes do coco babaçu tem potencial econômico na agropecuária. O farelo derivado do epicarpo, mesocarpo, e endocarpo do coco babaçu pode ser usado na confecção de rações como fonte alternativa de nutrientes capaz de substituir o milho e o farelo de soja na alimentação das aves, sem comprometer o desempenho, atendendo à necessidade dos produtores rural da região.

\section{Conclusão}

Mediante os resultados obtidos, observou-se que os associados da Associação dos Trabalhadores Agroextrativistas da Reserva Extrativista do Ciriaco (ATARECO) tem desperdiçado o potencial econômico do endocarpo por descartá-lo no processo de extrativismo do babaçu. É importante ressaltar que a busca por novas alternativas de utilização de todos os componentes do coco babaçu são ações que trabalham de maneira abrangente as vertentes do desenvolvimento sustentável.

Também, foi observado que a cadeia de produção é lenta devido a maior parte desse processo produtivo ser realizado de forma manual. Desta forma, evidencia-se que para impulsionar o processo de produção é necessário a incorporação de tecnologias nas atividades extrativistas com o intuito de suprir grandes demandas de produção. Portanto, substituir o modo de produção tradicional pelo processamento mecanizado e de baixo custo, no contexto do extrativismo do babaçu, se torna um aporte para o desenvolvimento econômico das comunidades que tem essa atividade como meio de subsistência. Assim, permitindo a inserção no mercado nacional e internacional, ofertando matéria prima para diferentes corporativas que fazem do 
babaçu insumo na fabricação de diferentes produtos.

Como perspectiva futura, pretende-se após a implementação do modelo proposto neste trabalho verificar sua eficácia por meio de um novo estudo, apresentar novas técnicas para o cultivo de culturas presentes na região que possam ser encaixadas no modelo produtivo, além de propor formação continuada aos profissionais da reserva extrativista.

\section{Referências}

Alvares, C. A., Stape, J. L., Sentelhas, P. C., Gonçalves, J. D. M., \& Sparovek, G. (2013). Köppen's climate classification map for Brazil. Meteorologische Zeitschrift, 22(6), 711-728.

Araujo, J. C., Ribeiro, N. M., Bezerra, K. C. B., \& Landim, L. A. dos S. R. (2020). Desenvolvimento de kefir em leite de coco babaçu. Research, Society and Development, 9(11), e3559119891.

Borba, J., \& Lüchmann, L. H. H. (2017). A representação política nos Conselhos Gestores de Políticas Públicas. Revista Brasileira de Gestão Urbana, 2(2), 229-246.

Brown, K., Kormondy, E. J., \& NEVES, W. (2002). Ecologia humana. Atheneu.

Carneiro, B. L. A., Arévalo-Pinedo, A., Scartazzini, L., Zuniga, A. D. G., \& Pinedo, R. A. (2014). Estudo da estabilidade do extrato hidrossolúvel" leite" de babaçu (Orbygnia speciosa) pasteurizado e armazenado sob refrigeração. Revista Brasileira de Fruticultura, 36(1), 232-236.

Chitarra, M. I. F., \& Chitarra, A. B. (2006). Pós-colheita de frutas e hortaliças: glossário. UFLA. https://www.bdpa.cnptia.embrapa.br/consulta/busca?b=ad\&biblioteca=CPATSA\&busca=autoria:\%22CHITARRA,\%20A.B.\%22

Costa, J. R., de Ávila Medeiros, T., Avelino-Capistrano, F., \& Santos, D. M. C. (2018). Parque Natural Municipal Chico Mendes: Percepção da população acerca de uma unidade de conservação de Proteção Integral na cidade do Rio de Janeiro. Ciência Atual-Revista Científica Multidisciplinar do Centro Universitário São José, 11(1).

da Silva Saraiva, A. F., de Oliveira, N. M., Pedroza Filho, M. X., \& Lopes, W. S. (2019). Cadeia produtiva do babaçu em Cidelândia-MA: uma análise a partir da abordagem de cadeia global de valor. Revista Brasileira de Gestão e Desenvolvimento Regional, 15(2)

de Almeida, M. W. B., Allegretti, M. H., \& Postigo, A. (2018). O legado de Chico Mendes: êxitos e entraves das Reservas Extrativistas. Desenvolvimento e Meio Ambiente, 48.

de Oliveira Melo, G. S., Barbosa, R. L., Barbosa, F. L., Barbosa, D. G., da Silva Castro, M. M., da Silva, M. A. C. N., \& Barbosa, M. D. C. L. (2020). Perfil alimentar e nutricional da população residente em comunidades quilombolas em um município do estado do Maranhão. Revista Eletrônica Acervo Saúde, 12(1), e2957-e2957.

de Sousa Sousa, A. A. (2020). Geografia e Mobilidade. Brazilian Geographical Journal, 11(1), 240-245.

dos Santos, L. N., Beraldo, K. A., \& Rodrigues, W. (2019). Gerenciamento de projetos na Reserva Extrativista do Ciriaco/MA: desempenho e participação. Revista Brasileira de Desenvolvimento Regional, 6(3), 93-110.

Hao, R., Yu, D., Liu, Y., Liu, Y., Qiao, J., Wang, X., \& Du, J. (2017). Impacts of changes in climate and landscape pattern on ecosystem services. Science of the Total Environment, 579, 718-728.

Homma, A. K. O. (2012). Plant extractivism or plantation: what is the best option for the Amazon?. Estudos Avançados, 26(74), 167-186.

Instituto Brasileiro de Geografia Estatística - IBGE (2019). Variável - Produção da extração vegetal e da silvicultura. https://sidra.ibge.gov.br/Tabela/289\#resultado.

Instituto Brasileiro de Geografia Estatística - IBGE (2020). Área da unidade territorial. https://cidades.ibge.gov.br/brasil/ma/cidelandia/panorama.

Instituto Brasileiro de Geografia Estatística - IBGE (2020). Site da Prefeitura de Cidelândia <www.prefeituracidelandia.com.br. https://cidades.ibge.gov.br/brasil/ma/cidelandia/historico.

Instituto Chico Mendes de Conservação da Biodiversidade - ICMBIO (2010). Reserva Extrativista do Ciriaco. 2010. http://www.icmbio.gov.br/portal/unidadesdeconservacao/biomas-brasileiros/mais-info/4746-resex-de-ciriaco.html.

Masullo, Y. A. G. Efetividade e a dinâmica territorial das unidades de conservação do Maranhão: novas perspectivas e outros olhares. 2019. (Tese de Doutorado - Universidade de Brasília).

May, P., Lustosa, M. C., \& Vinha, V. (2010). Economia do meio ambiente. Elsevier Brasil.

Meek, D., \& Simonian, L. T. (2017). Transforming space and society? The political ecology of education in the Brazilian Landless Workers' Movement's Jornada de Agroecología. Environment and Planning D: Society and Space, 35(3), 513-532.

Mercado Físico Rural - MF RURAL (2020). Conjunto de Máquinas para Quebrar Coco Babaçu. https://www.mfrural.com.br/detalhe/187640/conjunto-demaquinas-para-quebrar-coco-babacu.

Mercado Livre Brasil (2020). Seladora-manual-de-plastico-40cm-pfs-400. https://produto.mercadolivre.com.br/MLB-1025554778-seladora-manual-deplastico-40cm-pfs-400-_JM. 
Monteiro, A. R. (2020). Educação ambiental: um itinerário para a preservação do meio ambiente e a qualidade de vida nas cidades. Revista de Direito da Cidade, 12(1), 830-850.

Mora-Motta, A., \& Stellmacher, T. (2020). Tree plantations at the last resource frontiers: extractivism and territorialisation in southern chile1. 'Civilizing'Resource Investments and Extractivism: Societal negotiations and the role of law, $31,115$.

Oliveira, T. J. A. (2018) Gerenciamento de projetos na Reserva Extrativista do Ciriaco-MA: desempenho e participação. Revista brasileira de desenvolvimento regional, Blumenau, 93-110.

Patino, C. M. \& Ferreira, J. C. (2018). Critérios de inclusão e exclusão em estudos de pesquisa: definições e porque eles importam. Jornal Brasileiro de Pneumologia, 44(2), 84

Pereira, A. S., Shitsuka, D. M., Parreira, F. J., \& Shitsuka, R. (2018b). Metodologia da pesquisa científica. UFSM. https://repositorio.ufsm.br/bitstrea $\mathrm{m} /$ handle/ 1/15824/Lic_Computacao_Metodologia-Pesquisa-Cientifica.pdf?sequence=1.

Porro, R. (2019). A economia invisível do babaçu e sua importância para meios de vida em comunidades agroextrativistas. Boletim do Museu Paraense Emílio Goeldi. Ciências Humanas, 14(1), 169-188.

Refer Comercio máquinas e ferramentas - REFER (2020), Máquinas e ferramentas: Triturador Forrageiro TRF 400 2CV 110220V TRAPP. https://www.refercomercio.com.br/triturador-forrageiro-trf-400-super-trapp-2-0cv-monof-bivolt?

Ribeiro, N. B., \& Mittmann, S. (2020). Mulher, quebradeira de coco, militante na amazônia: constituição subjetiva e autoria em sou filha de quebradeira de coco babaçu. Organon, 35(70), 1-23.

Santos, F. D. R. P., Santos, M. G. B., Lucena, V. B., Viana, M. B., \& de Castro, A. D. A. P. (2020). Uso do óleo de coco babaçu (Attalea speciosa) como emoliente em formulação fitocosmética com ação hidratante. Revista Cereus, 12(4), 2-13.

Santos, L., Pizzio, A., \& Rodrigues, W. (2021). Plano de manejo e desenvolvimento: a experiência dos comunitários da Resex do Ciriaco na implementação de projetos Management and development plan: the experience of Ciriaco Resex communities in implementing projects. Informe GEPEC, 25(1), 27-45.

Sistema IBGE de Recuperação Automática - IBGE/SIDRA (2019). Variável - Quantidade produzida e valor da produção na extração vegetal, por tipo de produto extrativo. https://sidra.ibge.gov.br/Tabela/289\#resultado.

Soares, J. G., \& Arruda, P. (2018). Proteção de direitos humanos: o caso das quebradeiras de coco babaçu. Arquivos Brasileiros de Psicologia, 70(3), 213-231.

Solón, P. (2019). Alternativas sistêmicas: Bem Viver, decrescimento, comuns, ecofeminismo, direitos da Mãe Terra e desglobalização. Editora Elefante.

Teixeira, A. S. D. N. M., Teixeira, P. R. S., \& Eiras, C. (2018). Uso de Nanopartículas do Mesocarpo do Babaçu como Plataforma para Ancoragem de Enzimas no Desenvolvimento de Biossensores: um Mapeamento Tecnológico. Revista GEINTEC-Gestão, Inovação e Tecnologias, 8(1), 4217-4230

Teixeira, E., Ferreira, Á., Soldatelli, B., Trindade, F., Zangrande, H., Santos, M., \& Scheleder, R. (2020). Representações Sociais sobre Desenvolvimento Sustentável em Moradores do Sudoeste do Paraná. Enciclopédia Biosfera, 17(34).

Tsuji, A. E., Saito, R. T., \& Mori, R. S. F. (2019). Automação no agronegócio de pequeno porte: dispositivo para pesagem e empacotamento na cadeia produtiva de morango (Trabalho de Conclusão de Curso - Universidade Tecnológica Federal do Paraná).

Wintle, B. A., Kujala, H., Whitehead, A., Cameron, A., Veloz, S., Kukkala, A., \& Bekessy, S. A. (2019). Global synthesis of conservation studies reveals the importance of small habitat patches for biodiversity. Proceedings of the National Academy of Sciences, 116(3), 909-914.

Zhang, W., Chang, W. J., Zhu, Z. C., \& Hui, Z. (2020). Landscape ecological risk assessment of Chinese coastal cities based on land use change. Applied Geography, 117, 102174. 